\title{
Self-Regulatory Skills in Accepted and Rejected Students
}

\author{
Karla Hrbackova* and Irena Balaban Cakirpaloglu** \\ *Department of Pedagogical Sciences, Faculty of Humanities, Tomas Bata University in Zlín, Czech Republic \\ **National Institute for Further Education, Regional Office Olomouc, Czech Republic
}

\begin{abstract}
Being rejected by peers is not only hurtful, it can cause later emotional and behavioral problems. Unfortunately, peer rejection become a common part of school life. In addition, it is rather difficult to reintegrate rejected students to classroom, because it is necessary to apply mechanisms for regulating one's own behavior. These mechanisms may be undermined by peer rejection. The aim of the research was to identify the differences in the self-regulatory skills of peer rejected pupils compared to accepted classmates and reveal whether the failure in selfregulation is associated with peer preferences. For this purpose, a sociometric nomination method, the Failure of SelfRegulation Questionnaire and The Means-Ends Problem Solving (MEPS) were used. The MEPS procedure included 5 stories related to problem situations that students can experience in a school environment. A total of 1625 lower secondary school students (aged 11 - 15) from 20 schools took part in the research. The results imply that the level of use of students' self-regulatory skills is related to peer preference. Peer rejected students achieve lower levels of self-regulation than accepted classmates. The peer rejected student fail to self-regulation of behaviour, emotions and the regulation of will and attention, except of cognitive regulation in which no differences were detected between peer rejected students and accepted classmates. The results have implications for early prevention and intervention efforts to foster adaptive self-regulation and reduce the risk of later social rejection.
\end{abstract}

Keywords: lower secondary school students; peer preference; peer rejection; self-regulation; sociometric nomination. 